
GOTTFRIED WEBER

\title{
DAS NIBELUNGENLIED
}

\author{
PROBLEM UND IDEE
}

J.B. METZLERSCHE

VERLAGSBUCHHANDLUNG

STUT'TGART 
ISBN 978-3-476-99957-3

ISBN 978-3-476-99956-6 (eBook)

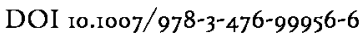

(C) 1963 Springer-Verlag GmbH Deutschland Ursprünglich erschienen bei J. B. Metzlersehe Verlagsbuchhandlung und Carl Ernst Poeschel Verlag GmbH in Stuttgart 1963 


\section{Georges ZiNK}

ALS AUSDRUCK PERSÖNLICHER HOCHSCHÄTZUNG

UND IM ZEICHEN DEUTSCH-FRANZÖSISCHER FREUNDSCHAFT ZUGEEIGNET 


\section{VORWORT}

Die Kernpartien des vorliegenden Buches sind in den Jahren 1952 und 1953 in Köln entstanden. Meine Berufung als Nachfolger Julius Schwieterings und die sofortige Übernahme des vakanten Frankfurter Lehrstuhls hinderten mich damals an der Fertigstellung. Inzwischen ist das Nibelungenlied mehrfach Gegenstand meiner Vorlesungen und Seminarübungen gewesen. Das I3. Kapitel habe ich in gekürzter Form als öffentliche Antrittsvorlesung im Jahre 1955 gehalten; das gleiche Kapitel war im Januar 1959 Gegenstand eines Gastvortrags an der Universität des Saarlandes; es lag schließlich im März I 96r einer Gastvorlesung an der Universität Lyon zugrunde.

Die endgültige Gestalt des Buches konnte erst in einem eigens dazu bewilligten Urlaubssemester im Winter $1962 / 63$ gewonnen werden. Für mannigfache Mitarbeit habe ich meinen Assistenten, Frau Dr. Barbara Könneker, Herrn Dr. Werner Hoffmann und Herrn Norbert Kern, zu danken. Das ro. Kapitel ist unter maßgeblicher Mitwirkung Barbara Könnekers abgefaßt worden; diese ist auch an den meisten der einzelnen Kapiteln angefügten Meditationen beteiligt. Zum Schluß ist das ganze Buch gemeinsam mit Frau Dr. Könneker noch einmal ergänzend durchgesehen worden. Werner Hoffmann hat meine Materialsammlung zum Exkurs II a vervollständigt und ist auch an den Exkursen II b-V erheblich beteiligt. Norbert Kern hat in der Hauptsache wertvolle technische Hilfe bei der Herstellung des endgültigen Manuskriptes geleistet.

Frankfurt am Main, im Juli $19^{6} 3$.

GOTTFRIED WEBER 


\section{IN HALT}

Einleitung ........................ I Kap. I: Kriemhilt .................... . s

Kap. II: Sîvrit ..................... . 22

Kap. III: Brünhilt . . . . . . . . . . . . . . . 34

Kap. IV: Hagen .. . . . . . . . . . . . . . . . . 43

Kap. V: Volkêr. . . . . . . . . . . . . . . . . 59

Kap. VI: Die Könige . . . . . . . . . . . . . . . . . . . . 67

Kap. VII: Rüedegêr. . . . . . . . . . . . . . . . . 85

Kap. VIII: riter .. . . . . . . . . . . . . . . . . . I03

Kap. IX: Gott. . . . . . . . . . . . . . . . . . . I2s

Kap. X: Dämonische Mächte ................ . I3s

Kap. XI: recke und belt . . . . . . . . . . . . . . . . . . I I I

Kap. XII: rebter beldes muot - Analyse und Perspektiven um Dietrîch von Bern . . . . . . . . . . . . . . . . . . . . . I6r

Kap. XIII: Der geistesgeschichtliche Ort des Nibelungenliedes . . . I $7^{1}$

Schlußmeditation . . . . . . . . . . . . . . . . . 195

Exkurs I: Zur Rüedegêr-Forschung . . . . . . . . . . . . . 199

Exkurs IIa: Statistische Darstellung: riter - recke - belt . . . . . . . . . . . . . 212

Exkurs IIb: recke. . . . . . . . . . . . . . . . . . . . 235

Exkurs III: $\operatorname{grim}(m e)$. . . . . . . . . . . . . . . . . 239

Exkurs IV: trôst ('trôst der Nibelunge’) . . . . . . . . . . . . . . . 242

Exkurs V: nôt ('der Nibelunge nôt') . . . . . . . . . . . . . 245

Register......................... 250 